\title{
Nucleotide Sequence of the Bacillus subtilis Developmental Gene SpoVE
}

\author{
By U. D. BUGAICHUK* AND P. J. PIGGOT $\dagger$ \\ Microbiology Unit, Department of Biochemistry, University of Oxford, South Parks Road, \\ Oxford OXI $3 Q U, U K$
}

(Received 25 October 1985; 19 February 1986)

\begin{abstract}
We have determined the nucleotide sequence of a $1159 \mathrm{bp}$ DNA fragment containing the spoVE locus of Bacillus subtilis. The locus contained a single open reading frame of 293 codons. On the basis of the predicted amino acid sequence, the product of the spoVE gene is believed to be a protein with an $M_{\mathrm{r}}$ of 31539 . The amino-terminal portion of the spoVE gene was used to construct a translational fusion with the $l a c Z^{\prime}$ gene. The hybrid spoVE-lacZ' gene was shown to be expressed in Escherichia coli and, therefore, it seems reasonable to conclude that the proposed open reading frame for the spoVE gene does indeed function in vivo.
\end{abstract}

\section{INTRODUCTION}

Bacterial endospore formation, triggered by nutrient limitation, is a primitive type of cellular differentiation. The study of this process in the Gram-positive bacterium Bacillus subtilis is particularly amenable to analysis as this organism is probably the most extensively studied of the differentiating prokaryotes.

The completion of the forespore engulfment, resulting in a two-celled structure, marks a significant stage in the process of developmental change in $B$. subtilis. Co-existence of the two genomes in such close proximity inevitably raises a number of questions about their participation in the subsequent biochemical and morphological events. Two major morphological changes that take place after compartmentalization are cortex formation, designated as stage IV, and deposition of the coat layers, designated as stage $V$. The existence of sporulation mutants which may be cortex ${ }^{+}$coat $^{-}$in one instance and cortex ${ }^{-}$coat $^{+}$in another, coupled with the results of epistasis experiments with double sporulation mutants, indicates the possibility that more than one dependent sequence of gene expression might be actively involved in the process of spore maturation at later stages (Coote \& Mandelstam, 1973; Piggot \& Coote, 1976).

There have been extensive studies of cloned sporulation-associated genes (Losick \& Youngman, 1984; Piggot, 1985). Most of these are concerned with genes expressed early in sporulation. The spo loci involved in the later stages of spore formation are, perhaps, of particular interest because of the complexity of the regulation of the developmental programme with two cell types involved, the mother cell and the forespore. Although most of the late loci are probably expressed only in the mother cell (Lencastre \& Piggot, 1979; Dancer \& Mandelstam, 1981), only one locus specific to the mother cell, spoVE, has been cloned (Yamada et al., 1983; Piggot et al., 1986).

We report here the nucleotide sequence of the spoVE locus and the proposed amino acid sequence for its product. We have established that this locus consists of a single gene $879 \mathrm{bp}$ long. The promoter-proximal portion of this gene was used to construct a translational fusion to the $l a c Z^{\prime}$ gene. The hybrid spoVE-lac $Z^{\prime}$ gene was expressed in Escherichia coli, providing strong evidence that the proposed open reading frame for the spoVE locus can be translated in vivo and, presumably, is functionally active.

† Present address: Department of Microbiology and Immunology, Temple University School of Medicine, 3400 North Broad Street, Philadelphia, Pennsylvania 19140, USA. 
Table 1. Escherichia coli strains

E. coli strain

JM103

JM107
Genotype

supE sbcB15 strA thi end $\triangle($ lac-pro $A B)\left[\mathrm{F}^{\prime}\right.$ traD36 proAB lac $\left.{ }^{\ddagger} \mathrm{Z} \triangle M 15\right]$

endAl gyrA96 hsdRI7 supE44 relAl thi, $\lambda^{-}$ $\Delta($ lac-pro $A B)\left[\mathrm{F}^{\prime}\right.$ traD36 pro $A B$ lacI $\left.\mathrm{Z} \Delta M 15\right]$
Source/reference

Messing et al. (1981)

Yanisch-Perron et al. (1985)

\section{METHODS}

Bacterial strains, phages and plasmids. The E. coli strains used are listed in Table 1.

Plasmid pPP7 is a derivative of the bifunctional vector $\mathrm{pHV} 33$, containing a $4.7 \mathrm{kbp}$ chromosomal fragment of B. subtilis (Piggot et al., 1986).

Plasmids pUB3 and pUB4 were constructed by subcloning the $1.35 \mathrm{kbp}$ Xhol fragment from pPP7 into the SalI site of pUC9 (Vieira \& Messing, 1982). The orientation of the insertion was verified by multiple digests with the appropriate restriction enzymes. A physical map of plasmid pUB4 is shown in Fig. 3. Plasmid pUB3 contains the same $X h o I$ fragment in the reverse orientation. The construction of plasmid pUB5 is discussed in Results.

Preparation of plasmid DNA. Plasmid DNA was prepared as described by Birnboim \& Doly (1979).

Transformation. E. coli strains were made competent and transformed by the method of Hanahan (1983). Recombinant MI 3 or pUC 9 vectors were selected as described by Fort \& Piggot (1984), except that ampicillin was used at a concentration of $50 \mu \mathrm{g} \mathrm{ml}^{-1}$ for plasmid selection.

Restriction enzyme analysis and isolation of specific DNA fragments. All restriction enzymes were purchased from BRL, New England Biolabs or Pharmacia. DNA ligase was purchased from Boehringer. Enzymes were used as recommended by the suppliers. Mapping of restriction sites was done by multiple enzyme cutting and analysis of the digestion products by agarose $(0.7-1.4 \%, \mathrm{w} / \mathrm{v})$ gel electrophoresis using Tris/borate buffer (Maniatis et al., 1982). Specific DNA fragments for sub-cloning or sequencing were isolated on horizontal $(0 \cdot 5-1 \%$, w/v) low melting point agarose slabs (BRL) as described by the manufacturers.

$D N A$ sequencing. Specific restriction fragments were sub-cloned into the appropriate M13 (mpl0, mpll or mp19) vector (Messing, 1983) and the nucleotide sequence was determined using the dideoxy chain termination method of Sanger et al. (1977). The sequencing kit was purchased from Amersham and was used in accordance with the supplier's recommendations.

\section{RESULTS}

The spoVE locus has been shown to be contained within a $2.9 \mathrm{kbp} E c o \mathrm{RI}$ fragment isolated by the 'prophage transformation' method in the temperature phage $\phi 105$ (Yamada et al., 1983). The independent isolation of this locus on a plasmid, pPP7 (Piggot et al., 1986), led us to the conclusion that the spoVE locus is probably situated on a $1.35 \mathrm{kbp} X h o I$ fragment and that its minimum size is about $560 \mathrm{bp}$. In order to identify the product(s) of the spoVE locus and to gain some information concerning the regulation of its expression we have determined the nuclelotide sequence of a 1159 bp DNA fragment covering an area where all known spoVE mutations were located. A detailed restriction map of the spoVE locus and the sequencing strategy are presented in Fig. 1. Plasmids pPP7, pUB3 and pUB4 served as sources of specific DNA fragments for sub-cloning into appropriately cleaved $\mathrm{M} 13$ vectors. The areas around all the restriction sites used for sequencing were re-sequenced from a nearby restriction site in order to avoid potential loss of a sequence due to closely spaced restriction sites.

The nucleotide sequence of the $1159 \mathrm{bp}$ chromosomal fragment is shown in Fig. 2. Analysis of the sequence has revealed that there is a single long open reading frame of 293 codons from which a protein $\left(M_{\mathrm{r}} 31539\right)$ can be translated. The open reading frame is preceded by a sequence which has a substantial degree of complementarity to the $3^{\prime}$ end of the $B$. subtilis $16 \mathrm{~S}$ rRNA and is, therefore, a potential ribosome binding site (Moran et al., 1982).

With a view to obtaining experimental evidence that we have correctly identified the open reading frame for the spoVE gene, we attempted to demonstrate that the $\mathrm{N}$-terminus of this frame can function as a translational start for synthesis of the $\alpha$-peptide of $\beta$-galactosidase (Messing et al., 1977). The hybrid plasmid pUB4 was chosen for subsequent intramolecular alterations aimed at creating a translational in-frame fusion of the spoVE and lac $Z^{\prime}$ genes. A 


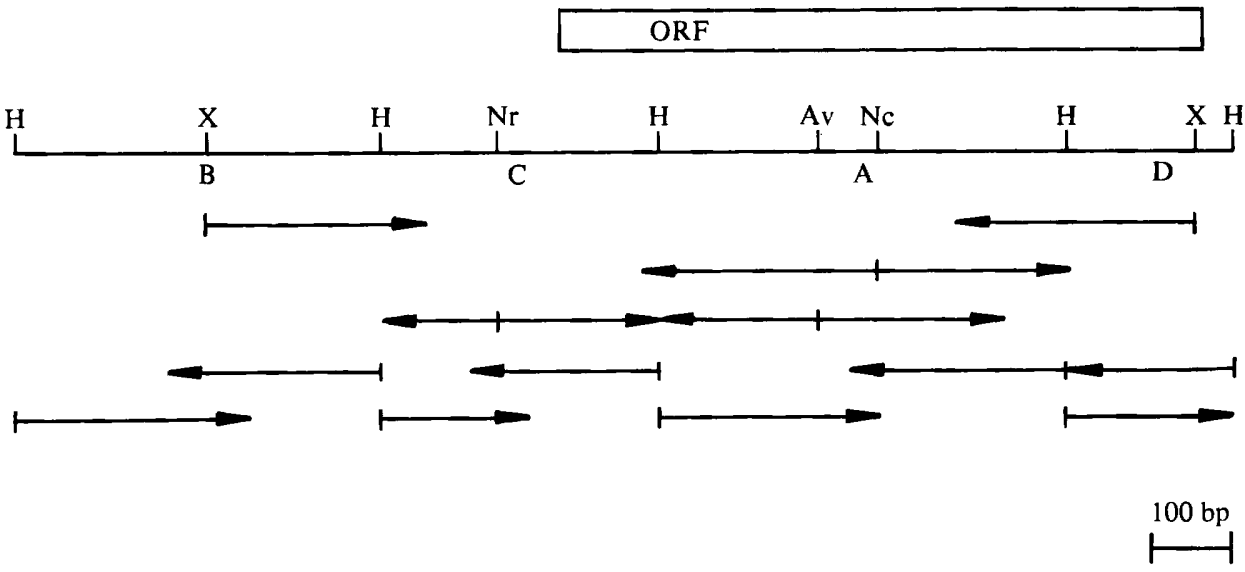

Fig. 1. Physical map of the B. subtilis spoVE locus. The top line indicates the positions of restriction sites used in sequencing experiments; horizontal arrows represent the sequencing strategy. The position of the large open reading frame (ORF) is indicated by the open box above the restriction map. Av, Aval; Nc, NcoI; Nr, NruI; X,XhoI; H, HindIII. The four HindIII fragments are lettered A-C in correspondence to their size.

1 HindIII

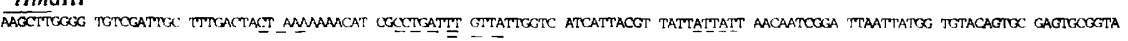

121

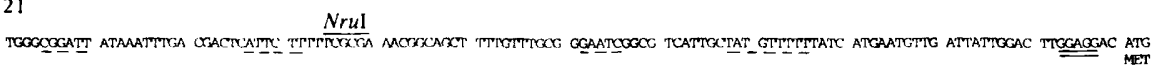

243

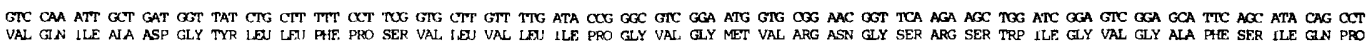
363

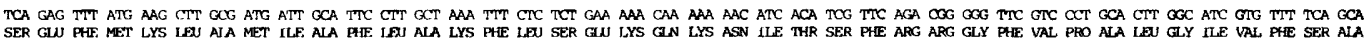
483

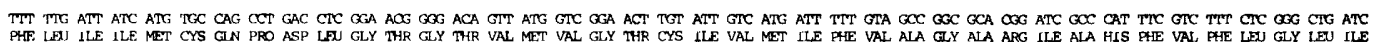
603

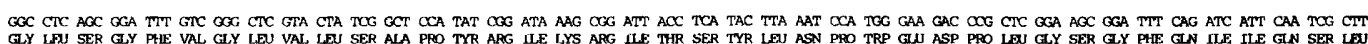
723

TAT GCA GTG GGG OCC GGC GGG TTG TTC GGA ATG GGG CTC GGA CAA AGC AGA CAG AAG TTC TTT TAT CTG CCT GAG OOG CAA ACA GAC TTT ATT TTC GCC ATC TTG TCA GAG GAG CTG GOC 843

TTT ATC GOG OGA ACA CIT ATT TTG CTC CTC TTC AGC GTC CTG CTG TGG AGA GGA ATC ACA ATT GOC CTT GCT GOC OCT GAT CTG TAC OGA AOC TTT GTC GCA GTC OCC ATT ATT TCA ATC PHE ILE GLY GLY THR LEI ILE LAJ LEU LEJ PHE SER VAL LEU LED TRP ARG GLY ILE ARG ILE ALA LEJ GLY AIA PRO ASP LEJ TYR GLY SER PFE VAL ALA VAL GLY ILE IIE SER MET 963

ATT GCC ATT CAA GTC ATG ATA AAT ATC GGC GTA GTC ACG GGC CTG ATT OCT GTA ACA GGC ATC ACG CTC COG TTT CTG AGC TAC GGA GGC TCT TCA TTG ACT CTA ATG CTG ATG GCA GTT 1083

GGT GTG CTG CTG AAT GTA AGC OGC TAC TOG AGG TAT TAA OGAATGTAT TTCCAAGCT OCTGTCTAAC ATGAACTT

Fig. 2. Nucleotide and predicted amino acid sequence of the $B$. subtilis spoVE locus (only the nontranscribed strand is shown). The sequence was determined on both strands. The strong ribosomebinding site is doubly underlined, The predicted amino acid sequence is shown using standard three letter abbreviations. Broken lines indicate the putative promoter sequences.

$1.35 \mathrm{kbp} X h o I$ fragment, residing on this plasmid, is in the same translational orientation as the lac $Z^{\prime}$ gene and, according to our sequencing data, does not contain any obvious transcriptional terminators. However, the translational phase of the spoVE open reading frame does not coincide with that of the lac $Z^{\prime}$ gene and, indeed, colonies containing pUB4 appear colourless on 


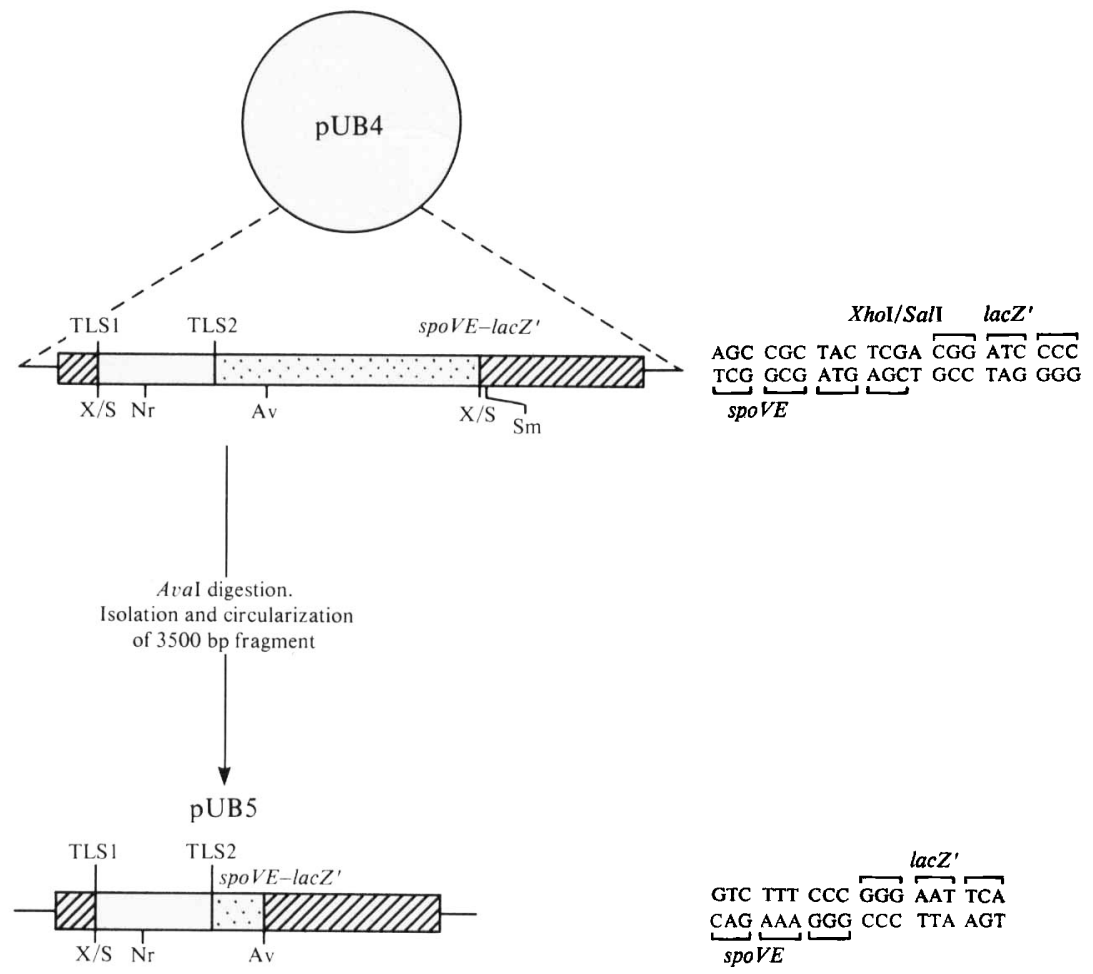

Fig. 3. Construction of spoVE-lac $Z^{\prime}$ translational gene fusion. The upper portion of the figure shows the structure of plasmid pUB4. The fragment of the sequence, shown on the right, represents the junction site and demonstrates the frame shift leading to translational failure. The proposed structure of plasmid pUB5 after excision of DNA between AvaI and SmaI ( $A v a I, X m a I)$ sites of pUB4 is shown in the lower portion of the figure. The sequence across the new junction site is presented on the right. The hatched boxes indicate the lac $Z^{\prime}$ gene. The stippled box represents the area downstream from spoVE translational start (TLS2), while the open box indicates the sequence upstream from its ribosome binding site. The direction of translation is from left to right in all cases. Av, AvaI ; X, XhoI;S, SalI; Sm, SmaI; Nr, NruI; TLS1, translational start of the lac $Z^{\prime}$ gene.

medium supplemented with X-gal. We postulated that correlation of the frame shift and reduction in size of the spoVE gene portion could lead to at least partial restoration of the $\alpha$ complementation function of a hybrid peptide (Fig. 3). The experimental approach to test this hypothesis was largely influenced by our discovery that the AvaI site within the spoVE gene and the AvaI (SmaI, XmaI) site in the multiple covalence site (MCS) area of the vector are in the same translational phase, so that after removal of the DNA fragment between these sites, rejoining of the remaining ends would create an in-frame junction between the spoVE and lac $Z^{\prime}$ genes.

Plasmid pUB4 was cut by $A v a \mathrm{I}$ and the $3.5 \mathrm{kbp}$ fragment was isolated on low melting point agarose. The purified fragment was circularized by T4 DNA ligase and introduced into $E$. coli strain JM103. Altogether, 56-ampicillin resistant transformants appeared on a selective medium containing X-gal and 53 of them showed pale blue colouration. Ten pale blue clones that we analysed contained a plasmid of $3.5 \mathrm{kbp}$. This new plasmid was designated pUB5. The identity of the remaining $B$. subtilis chromosomal fragment in the plasmid was confirmed by the presence of a unique $N r u$ I site which is $80 \mathrm{bp}$ upstream from the translational start point of the spoVE gene. We verified that this plasmid had the expected structure by subcloning the $0.8 \mathrm{kbp} P$ stIEcoRI fragment of plasmid pUB5 into M13 mp11 and determining the sequence of the junction site between the spoVE and lac $Z^{\prime}$ genes. 


\begin{tabular}{|c|c|c|}
\hline Position $\dagger$ & Holoenzyme & $\cdot-10 '$ \\
\hline $38-50$ & $\mathrm{E} \sigma^{28}$ & $\begin{array}{cr}\text { CTAAA } & \text { CC } \\
* * * * * & * * \\
* * * * * & * \\
\text { ACTAAAAAAACATCGCCTGATTT }\end{array}$ \\
\hline $49-79$ & $\mathrm{E} \sigma^{43}$ & $\begin{array}{lr}\text { TTGACA } & \text { TATAAT } \\
* * * & * * * * \\
\text { TTGTTATTGGTCATCATTACGTTATTATTAT }\end{array}$ \\
\hline $125-155$ & $\mathrm{E} \sigma^{37}$ & $\begin{array}{cc}\text { AGNNTT } & \text { GGNATTNTT } \\
* & * * \\
\text { CGGATTATAAATTTGACGACTCATTCTTTTT }\end{array}$ \\
\hline $181-207$ & $\mathrm{E} \sigma^{32}$ & $\begin{array}{crl}\text { AAATC } & \text { TANTGNTTNTA } \\
* * * * & * * & * * * * * \\
\text { GGAATCGGCGTCATTGCTA } & \text { TGTTTTTT }\end{array}$ \\
\hline
\end{tabular}

Fig. 4. Regions showing homology to known $B$. subtilis promoters. Consensus sequences of the $B$. subtilis promoters controlled by minor forms of RNA polymerase were taken from Cowing et al. (1985). Nucleotides that match are designated with an asterisk $(*)$. $\dagger$, The position is given in correspondence to the sequence presented in Fig. 2 . $\ddagger$, The one residue gap has been introduced in order to make homology more explicit.

\section{DISCUSSION}

Two of the spoV loci have been cloned so far: spoVG (Segall \& Losick, 1977) and spoVA (Savva \& Mandelstam, 1984). A substantial amount of data concerning transcriptional aspects of the spoVG locus is now available (Banner et al., 1983). Fort \& Errington (1985) have determined the nucleotide sequence of the spoVA locus, which is the largest polycistronic sporulation operon yet characterized.

In this paper we present the nucleotide sequence of another stage $\mathrm{V}$ locus, spoVE, and the predicted amino acid sequence for its product (Fig. 2). The identification of this DNA fragment as the spoVE locus is unambiguous since all spoVE mutations tested map within this sequence (Piggot et al., 1986). The entire sequence of 1159 bp (Fig. 2) is based on sequencing of individual clones, as indicated in Fig. 1. Computer analysis has revealed one long open reading frame consisting of 293 codons. It starts with an ATG codon at position 240-242. Two nucleotides upstream there is a strong ribosome binding site, GGAGG, for which the free energy of base pairing $(\Delta G)$ with the $3^{\prime}$ end of the $B$. subtilis $16 \mathrm{~S} \mathrm{rRNA}$ is calculated to be $-14.4 \mathrm{kcal} \mathrm{mol}^{-1}$ $\left(-60.3 \mathrm{~kJ} \mathrm{~mol}^{-1}\right)$ using the rules of Tinoco et al. (1973). This $\Delta G$ value falls into a range published for Bacillus (Moran et al., 1982; Fort \& Piggot, 1984). An interesting feature of this part of the sequence is the unusual closeness of the ribosome binding site to the translational start point.

Potential transcription initiation signals can be discerned from the determined sequence. Preceding the spoVE gene, within 207 bp upstream from the ribosome binding site, are four regions that have a substantial degree of homology to known $B$. subtilis promoters. The positions of these regions are indicated in Fig. 4. The sequences at positions 38-50, 125-155 and 181-207 display quite a close resemblance to promoters recognized by $\mathrm{E} \sigma^{28}, \mathrm{E} \sigma^{37}$ and $\mathrm{E} \sigma^{32}$ respectively. All of them appear to belong to the class of promoters utilized by minor forms of RNA polymerase holoenzyme. The sequence at position 49-79 exhibits substantial homology with the consensus sequence of promoters recognized by the major form of holoenzyme $E \sigma^{43}$. Although the exact position(s) of the transcriptional start point(s) will require further investigation, the arrangement of $\sigma^{37}$ and $\sigma^{32}$ promoter sequences upsteam from the translocational start point of the spoVE gene is reminiscent of the regulatory region of the spoVG locus, which includes the same two types of promoters (Banner et al., 1983).

A great deal of information concerning various aspects of the expression of sporulation genes can be gained by fusing the gene in question to a second gene, whose product can be assayed 


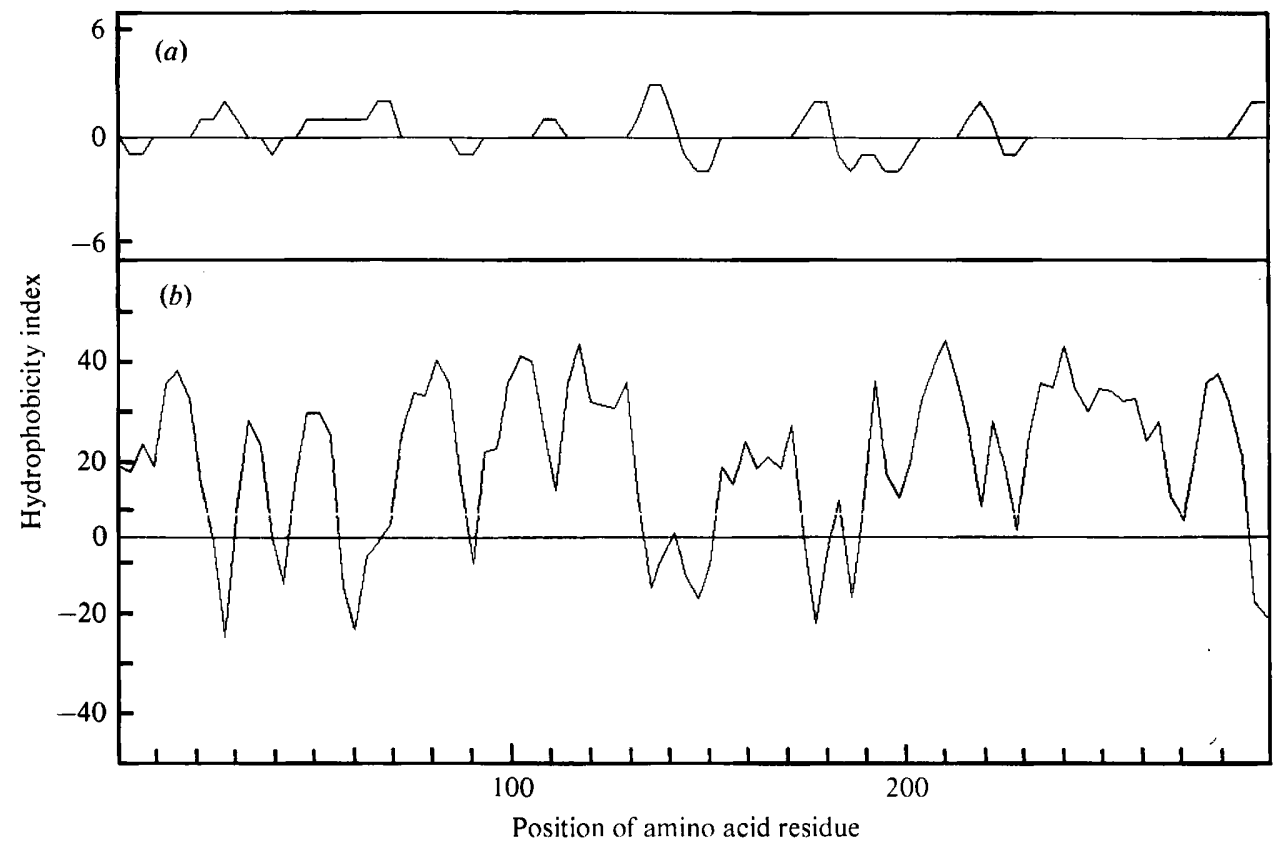

Fig. 5. Graphical display of the structural properties predicted for the spoVE gene product. (a) The distribution of charged residues along the amino acid sequence. (b) The hydrophatic character of the predicted protein (Kyte \& Doolittle, 1982; R. Staden, personal communication). Both profiles were obtained with a segment of seven residues.

quantitatively. We have employed this technique in order to establish whether or not the open reading frame we propose for the spoVE locus is translated in vivo. Analysis of the spoVE-lac $Z^{\prime}$ structure contained on plasmid pUB4 in terms of translational possibilities provides a convincing explanation for the inability of this plasmid to synthesize a functionally active $\alpha$ peptide. On the basis of our sequencing data we conclude that disruption of $\alpha$-peptide synthesis has a translational and not a transcriptional basis. Translation from the original lac $Z^{\prime}$ start point (TLS1) comes to a halt shortly after passing the junction site (XhoI/SalI), resulting in a peptide containing 11 amino acids. Translation from the spoVE start point (TLS2) will not produce functional $\alpha$-peptide because of the frame shift (Fig. $3 a$ ). In both cases synthesis of a hybrid protein containing $\alpha$-peptide as a $\mathrm{C}$-terminus appears not to be possible. However, when a portion of the DNA between the AvaI site in the spoVE gene and the AvaI (SmaI, $X \mathrm{maI})$ site in the MCS area is removed, the resulting plasmid, pUB5, is apparently able to produce at least partially active hybrid $\alpha$-peptide, indicated by the appearance of pale blue colouration when plasmid-containing colonies are plated on agar supplemented with X-gal.

We conclude that this excision has created a new in-frame junction between the spoVE and lac $Z^{\prime}$ genes (Fig. $3 b$ ). Therefore, while the translation from TLS1 remains impeded, translation from TLS2 can now lead to the synthesis of a functionally active hybrid $\alpha$-peptide whose aminoterminus is substituted for the 118 amino acid stretch of the spoVE gene product. It seems reasonable, therefore to conclude that the proposed open reading frame for the spoVE gene does indeed function in vitro.

The protein product predicted from the nucleotide sequence appears to be quite unusual and shows several features of interest. The ratio of acidic (glutamate, asparate) or basic (lysine, arginine, histidine) residues is 0.55 , indicating a rather basic protein with a calculated isoelectric point of $9 \cdot 1$. This protein also has a high content of hydrophobic residues, which is a 
characteristic feature of membrane-bound proteins (Fig. 5). Moreover, it contains several stretches of 18-24 hydrophobic residues flanked by charged residues and this is strongly suggestive of membrane-spanning amino acid sequences (Eisenberg et al., 1984).

The availability of the entire nucleotide sequence of the spoVE locus should facilitate the rapid elucidation of those features that are important in the regulation of expression of this gene.

We are grateful to Professor J. Mandelstam and Dr M. D. Yudkin for critical reading of the manuscript and many helpful discussions. We thank Drs J. Errington, J. Gagnon, J. Rees and M. J. Geisow for help with computer analysis and advice. U.D.B. acknowledges the technical help of Mrs M. Deadman with sequencing experiments. This work was supported by grants from the Science and Engineering Research Council.

\section{REFERENCES}

Banner, C. D. B., Moran, C. P., JR \& Losick, R. (1983). Deletion analysis of a complex promoter for a developmentally regulated gene from Bacillus subtilis. Journal of Molecular Biology 168, 351-365.

Birnborm, H. C. \& Doly, J. (1979). A rapid alkaline extraction procedure for screeing recombinant plasmid DNA. Nucleic Acids Research 7, 1513-1523.

Coote, J. G. \& Mandelstam, J. (1973). Use of constructed double mutants for determining the temporal order of expression of sporulation genes in Bacillus subtilis. Journal of Bacteriology 114, 12541263.

Cowing, D. W., Bardwell, J. C. A., Craig, E. A., Woolford, C., Hendrix, R. W. \& Gross, C. A. (1985). Consensus sequence for Escherichia coli heat shock gene promoters. Proceedings of the National Academy of Sciences of the United States of America 82, 2679-2683.

DANCER, B. N. \& Mandelstam, J. (1981). Complementation of sporulation mutations in fused protoplasts of Bacillus subtilis. Journal of General Microbiology 123, 17-26.

EisenberG, D., Schwarz, E., Komaromy, M. \& W ALL, R. (1984). Analysis of membrane and surface protein sequences with the hydrophobic moment plot. Journal of Molecular Biology 179, 125-142.

FORT, P. \& ERRINGTON, J. (1985). Nucleotide sequence and complementation analysis of a polycistronic sporulation operon, spoVA, in Bacillus subtilis. Journal of General Microbiology 131, 1091-1105.

ForT, P. \& Piggot, P. J. (1984). Nucleotide sequence of sporulation locus spollA in Bacillus subtilis. Journal of General Microbiology 130, 2147-2153.

HANAHAN, D. (1983). Studies on transformation of Escherichia coli with plasmids. Journal of Molecular Biology 166, 557-580.

KYTE, J. \& Doolittle, R. F. (1982). A simple method for displaying the hydropathic character of a protein. Journal of Molecular Biology 157, 105-132.

Lencastre, H. DE \& Piggot, P. J. (1979). Identification of different sites of expression for spo loci by transformation of Bacillus subtilis. Journal of General Microbiology 114, 377-389.

Losick, R. \& Youngman, P. (1984). Endospore formation in Bacillus. In Microbial Development, pp. 63-88. Edited by R. Losick \& L. Shapiro. Cold Spring Harbor, NY: Cold Spring Harbor Laboratory.
Maniatis, T., Fritsch, E. F. \& Sambrook, J. (1982). Molecular Cloning, a Laboratory Manual. Cold Spring Harbor, NY: Cold Spring Harbor Laboratory.

MEssing, J. (1983). New M13 vectors for cloning. Methods in Enzymology 101, 20-78.

Messing, J., Gronenbron, B., Muller-Hill, B. \& HoFsCHNEIDER, P. H. (1977). Filamentous coliphage M13 as a cloning vehicle: insertion of a HindII fragment of the lac regulatory region in $\mathrm{M} 13$ replicative form in vitro. Proceedings of the National Academy of Sciences of the United States of America, 74, 3642-3646.

Messing, J., Crea, R. \& Seeburg, P. H. (1981). A system for shotgun DNA sequencing. Nucleic Acids Research 9, 309-321.

Moran, C. P., Jr, LANG, N., Le Grice, S. F. J., Lee, G., Stephens, M., Sonenshein, A. L., Pero, J. \& Losick, R. (1982). Nucleotide sequences that signal the initiation of transcription and translation in Bacillus subtilis. Molecular and General Genetics 186, 339-346.

PIGGOT, P. J. (1985). Sporulation of Bacillus subtilis. In: The Molecular Biology of the Bacilli, vol. 2, pp. 73108. Edited by D. A. Dubnau, New York: Academic Press.

Piggot, P. J. \& Coote, J. G. (1976). Genetic aspects of bacterial endospore formation. Bacteriological Reviews 40, 908-962.

Piggot, P. J., ChaK, K.-F. \& Bugaichuk, U. D. (1986). Isolation and characterization of clones of the spoVE locus of Bacillus subtilis. Journal of General Microbiology 132, 1875-1881.

SANGer, F., Nicklen, S. \& Coulson, A. R. (1977). DNA sequencing with chain terminating inhibitors. Proceedings of the National Academy of Sciences of the United States of America 74, 5463-5467.

Savva, D. \& Mandelstam, J. (1984). Cloning of the Bacillus subtilis spoIIA and spoVA genes in phage $\phi 105 D I: 1 \mathrm{t}$. Journal of General Microbiology 130, 2137-2145.

SEgall, J. \& Losick, R. (1977). Cloned Bacillus subtilis DNA containing a gene that is activated early during sporulation. Cell 11, 751-761.

Tinoco, I., JR, Borer, P. N., DANGler, B., LeVine, M. D., Uhlenbeck, O. C., Crothers, D. M. \& Gralla, J. (1973). Improved estimation of secondary structure in ribonucleic acids. Nature, London 246, $40-41$. 
Vieira, J. \& Messing, J. (1982). The pUC plasmids and M13 mp 7 derived system for insertion mutagenesis and sequencing with synthetic universal primers. Gene 19, 259-268.

Yamada, H., ANaGUChI, H. \& Kobayashi, Y. (1983).

Cloning of the sporulation gene spoVE in Bacillus subtilis. Journal of General and Applied Microbiology 29, 477-486.

Yanisch-Perron, C., Vieira, J. \& Messing, J. (1985). Improved M13 phage cloning vectors and host strains: nucleotide sequences of the $\mathrm{M} 13 \mathrm{mp} 18$ and pUC19 vectors. Gene 33, 103-119. 